\title{
THE POPULATION GENETICS OF "SEX-RATIO" IN DROSOPHILA PSEUDOOBSCURA
}

\author{
A. W. F. EDWARDS \\ (Eugenics Society Darwin Research Fellow) \\ Department of Genetics, University of Cambridge
}

\section{INTRODUCTION}

Received 20.iii.6I

BenNetT (1958), Barker (1958) and Shaw (I959) have all recently discussed the population genetics of the X-linked condition "sexratio" in Drosophila pseudoobscura. The purpose of the present paper is to put forward a mathematical model considered more appropriate than that used by Bennett and Shaw, and to examine the subject more closely than did Barker.

The condition " sex-ratio " was first studied in detail by Gershenson (1928) in Drosophila obscura, and later by Sturtevant and Dobzhansky (1936) and Dobzhansky (1943) in D. pseudoobscura. Sturtevant and Dobzhansky showed that "sex-ratio" is associated with an inversion, and is thus not simple genetically. However, in the present paper the words "gene" and "locus" will frequently be applied to it in order to simplify the mathematical arguments, but its more complex nature should be borne in mind. An early record of a similar condition in Drosophila affinis occurs in The genetics of Drosophila by Morgan, Bridges and Sturtevant (1925).

Briefly, males carrying the abnormal $\mathrm{X}$-chromosome $\left(\mathrm{X}_{r}\right)$ produce few or no sons, but nearly twice as many daughters as are produced by normal males. Gershenson remarked that, in the absence of differential viability, the abnormal chromosome would increase in a population until there were no males left. Sturtevant and Dobzhansky also noted this, but added that "the algebraic analysis of populations containing 'sex-ratio" is difficult, and may best be postponed . . .". They found that the abnormal chromosome was present in apparent equilibrium in natural populations.

Wallace (1948) conducted an extensive series of experiments in which he ran population cages and also attempted to estimate the viabilities of the several genotypes directly. It is the results of these experiments to which Bennett, Barker and Shaw have applied their models.

\section{POPULATION MODEL}

The study of selection on loci which affect the sex-ratio is made difficult by the relevance of arguments concerning the expenditure incurred by parents in rearing offspring, as has been emphasised by Bodmer and Edwards (1960). In order to avoid these difficulties in the present problem it is necessary to postulate that the individual 
expenditures on male and female offspring are equal, and that there is no differential viability amongst the offspring between fertilisation and the end of the period of parental expenditure. These restrictions on the model will be discussed later.

Let the genotypes $\mathrm{XX}, \mathrm{XX}_{r}, \mathrm{X}_{r} \mathrm{X}_{r}, \mathrm{XY}$ and $\mathrm{X}_{r} \mathrm{Y}$ have effective frequencies at sexual maturity $u, v, w, x$ and $y$, where $u+v+w+x+y=\mathrm{I}$, and let their relative viabilities be $\mathrm{I}, a, b$, I and $c$, respectively. Further, let the proportion of males born to $\mathrm{X}_{r} \mathrm{Y}$ fathers be $(\mathrm{I}-t)$. Then the

TABLE I

Derivation of genotype frequencies

\begin{tabular}{|c|c|c|c|c|c|c|c|}
\hline Mating & Frequency & $\begin{array}{l}\text { Offspring } \\
\text { Viability }\end{array}$ & $\underset{\mathrm{I}}{\mathrm{XX}}$ & $\underset{a}{\mathrm{XX}_{r}}$ & $\underset{b}{\mathrm{X}_{r} \mathrm{X}_{r}}$ & $\underset{\mathrm{I}}{\mathrm{XY}}$ & $\underset{c}{\mathrm{X}_{r} \mathrm{Y}}$ \\
\hline $\begin{array}{l}\mathrm{XY} \times \mathrm{XX} \\
\mathrm{XY} \times \mathrm{XX}_{r} \\
\mathrm{XY} \times \mathrm{X}_{r} \mathrm{X}_{r} \\
\mathrm{X}_{r} \mathrm{Y} \times \mathrm{XX} \\
\mathrm{X}_{r} \mathrm{Y} \times \mathrm{XX}_{r} \\
\mathrm{X}_{r} \mathrm{Y} \times \mathrm{X}_{r} \mathrm{X}_{r}\end{array}$ & $\begin{array}{l}x u \\
x v \\
x w \\
y u \\
y v \\
y w\end{array}$ & $\begin{array}{l}\ldots \\
\ldots \\
\ldots \\
\ldots \\
\ldots\end{array}$ & $\begin{array}{l}\frac{1}{2} \\
\frac{1}{4} \\
\ldots \\
\ldots \\
\ldots \\
\ldots\end{array}$ & $\begin{array}{l}\dddot{1} \\
\frac{1}{2} \\
\frac{1}{2} \\
\frac{1}{2} t \\
\cdots\end{array}$ & $\begin{array}{l}\cdots \\
\cdots \\
\cdots \\
\dddot{i} \\
\frac{1}{2} t\end{array}$ & $\begin{array}{c}\frac{1}{2} \\
\frac{1}{4} \\
\cdots \\
(I-t) \\
\frac{1}{2}(\mathrm{I}-t) \\
\cdots\end{array}$ & $\begin{array}{c}\dddot{1} \\
\frac{1}{2} \\
\cdots \\
\frac{1}{2}\left(\begin{array}{l}1 \\
(1-t)\end{array}\right)\end{array}$ \\
\hline
\end{tabular}

relative frequencies of the genotypes in the next generation can be found from table $\mathrm{I}$. These are given by

$$
\begin{aligned}
\mathrm{T} u^{\prime} & =\frac{1}{2} x\left(u+\frac{1}{2} v\right) \\
\mathrm{T} v^{\prime} & =a\left(\frac{1}{2} x\left(w+\frac{1}{2} v\right)+t y\left(u+\frac{1}{2} v\right)\right) \\
\mathrm{T} w^{\prime} & =b t y\left(w+\frac{1}{2} v\right) \\
\mathrm{T} x^{\prime} & =\left(\frac{1}{2} x+(\mathrm{I}-t) y\right)\left(u+\frac{1}{2} v\right) \\
\mathrm{T} y^{\prime} & =c\left(\frac{1}{2} x+(\mathrm{I}-t) y\right)\left(w+\frac{1}{2} v\right),
\end{aligned}
$$

where $\mathrm{T}$ is such that $u^{\prime}+v^{\prime}+w^{\prime}+x^{\prime}+y^{\prime}=\mathrm{I}$. The effective gene ratios at maturity in the next generation are therefore given by

$$
r_{f}^{\prime}=\frac{a\left(\frac{1}{2} x\left(w+\frac{1}{2} v\right)+t y\left(u+\frac{1}{2} v\right)\right)+2 b t y\left(w+\frac{1}{2} v\right)}{x\left(u+\frac{1}{2} v\right)+a\left(\frac{1}{2} x\left(w+\frac{1}{2} v\right)+t y\left(u+\frac{1}{2} v\right)\right)}
$$

for females and $r_{m}^{\prime}=c\left(w+\frac{1}{2} v\right) /\left(u+\frac{1}{2} v\right)$ for males. The original gene ratios are given by $r_{f}=\left(w+\frac{1}{2} v\right) /\left(u+\frac{1}{2} v\right)$ and $r_{m}=y / x$. From these relations

$$
r_{f}^{\prime}=\frac{a\left(\frac{1}{2} r_{f}+t r_{m}\right)+2 b t r_{f} r_{m}}{\mathrm{I}+a\left(\frac{1}{2} r_{f}+t r_{m}\right)} \text { and } r_{m}^{\prime}=c r_{f} \ldots \text { (I) and (2) }
$$

At equilibrium $r_{f}^{\prime}=r_{f}=r_{e f}$ (say) and $r_{m}^{\prime}=r_{m}=r_{e m}$, so that $r_{e m}=c r_{e f}$, and hence

$$
r_{e f}=\frac{a r_{e f}\left(\frac{1}{2}+c t\right)+2 b c t r^{2}{ }_{e f}}{a r_{e f}\left(\frac{1}{2}+c t\right)+\mathrm{I}}
$$

Since $r_{e f}$ is not zero, for then the equilibrium would be trivial,

$$
r_{e f}=\frac{a(\mathrm{I}+2 c t)-2}{a(\mathrm{I}+2 c t)-4 b c t .}
$$


This is the equilibrium effective female gene ratio at maturity. If there is no differential fertility between genotypes of the same sex, then it is the actual ratio at maturity. The male ratio has already been given by $r_{e m}=c r_{e f}$.

The equilibrium gene ratios before zygotic selection, $s_{e f}$ and $s_{e m}$, may be found by putting the ratios after selection in equations (I) and (2) and setting $a=b=c=\mathrm{I}$, whence

$$
s_{e f}=\frac{\frac{1}{2} r_{e f}+t r_{e m}+2 t r_{e f} r_{e m}}{\mathrm{I}+\frac{1}{2} r_{e f}+t r_{e m}} \text { and } s_{e m}=r_{e f} .
$$

Since the genotype frequencies may be completely expressed in terms of the gene ratios of the previous generation, as is shown below, it is clear that the problem may be exhaustively examined mathematically in terms of these ratios.

$$
\begin{aligned}
\mathrm{T}^{*} u^{\prime} & =\frac{1}{2} \\
\mathrm{~T}^{*} v^{\prime} & =a\left(\frac{1}{2} r_{f}+t r_{m}\right) \\
\mathrm{T}^{*} w^{\prime} & =b t r_{f r_{m}} \\
\mathrm{~T}^{*} x^{\prime} & =\left(\frac{1}{2}+(\mathrm{I}-t) r_{m}\right) \\
\mathrm{T}^{*} y^{\prime} & =c\left(\frac{1}{2}+(\mathrm{I}-t) r_{m}\right) r_{f} .
\end{aligned}
$$

In particular, the conditions that the equilibrium is stable may be evaluated by examining the properties of the gene ratios when they are near to their equilibrium values. It transpires that the equation for the latent roots of the generation matrix of the gene ratios near equilibrium is

$$
\lambda^{2}-2 \lambda \frac{4 b c t(a c t-1)+a}{a^{2}(\mathrm{I}+2 c t)^{2}-8 b c t}-4 c t \frac{b(a-2)+a}{a^{2}(\mathrm{I}+2 c t)^{2}-8 b c t}=0,
$$

the condition for stability being that the absolute values of both roots must be less than $I$.

If the factor $2 c t$ is regarded as an overall viability, this equation is formally identical to that considered by Bennett, who stated, without proof, that the equilibrium is stable if and only if both the numerator and denominator of the expression for $r_{e f}$ are positive, that is if

$$
a(\mathrm{I}+2 c t)>2 \text { and } a(\mathrm{I}+2 c t)>4 b c t .
$$

A proof of this statement follows.

Putting $a(\mathrm{I}+2 c t)=\mathrm{H}, 2=\mathrm{B}$ and $4 b c t=\mathrm{A}, r_{e f}=(\mathrm{H}-\mathrm{B}) /(\mathrm{H}-\mathrm{A})$ the notation being specifically chosen to draw an analogy with the autosomal case.

Writing the equation for the latent roots as $\lambda^{2}+\mathrm{L} \lambda+\mathrm{M}=\mathrm{o}$ it is easy to show that

and hence that

$$
\mathrm{L}+\mathrm{M}=-\frac{\mathrm{B}(\mathrm{H}-\mathrm{A})+\mathrm{A}(\mathrm{H}-\mathrm{B}),}{\mathrm{H}^{2}-\mathrm{AB}}
$$

$$
\mathrm{I}+\mathrm{L}+\mathrm{M}=\frac{(\mathrm{H}-\mathrm{A})(\mathrm{H}-\mathrm{B}),}{\mathrm{H}^{2}-\mathrm{AB}}
$$


From these relations, if $\mathrm{H}>\mathrm{A}$ and $\mathrm{H}>\mathrm{B}$ then $\mathrm{L}+\mathrm{M}<0$ and $\mathrm{I}+\mathrm{L}+\mathrm{M}>0$, and if $\mathrm{H}<\mathrm{A}$ and $\mathrm{H}<\mathrm{B}$ then $\mathrm{L}+\mathrm{M}<0$ and $\mathrm{I}+\mathrm{L}+\mathrm{M}<0$. Furthermore, the reverse holds true, since $\mathrm{H}-\mathrm{A}$ and $\mathrm{H}-\mathrm{B}$ must be of the same sign for the female gene ratio to be positive.

The next stage in the proof is to show that $-\mathrm{I}<\mathrm{L}<0$ and $-\mathrm{I}<\mathrm{M}<\mathrm{o}$ for all possible values of the viabilities that do not lead to trivial equilibria.

Suppose $\mathrm{H}>\mathrm{A}, \mathrm{H}>\mathrm{B}$. Then the denominators of $\mathrm{L}$ and $\mathrm{M}$, $\mathrm{H}^{2}-\mathrm{AB}$, are positive. Further, since $a(\mathrm{I}+2 c t)>4 b c t$ and $a(\mathrm{I}+2 c t)>2$, $a \mid b>4 c t /(\mathrm{I}+2 c t)$ and $a>2 /(\mathrm{I}+2 c t)$. Hence $a+a \mid b>2$, or $(a-2)+$ $a \mid b>0$. Therefore the numerator of $\mathrm{L},-4 c t(b(a-2)+a)$, is negative, and $\mathrm{L}<\mathrm{o}$.

Similarly, since $a(\mathrm{I}+2 c t)>2,4 c t(a c t-\mathrm{I})>-4 c t /(\mathrm{I}+2 c t)$. Hence $4 c t(a c t-\mathrm{I})+a \mid b>0$; the numerator of $\mathrm{M},-2(4 b c t(a c t-\mathrm{I})+a)$, is negative, and $\mathbf{M}<0$.

Again, clearly

or

$$
\begin{aligned}
& a(\mathrm{I}+2 c t)+2 a c t(\mathrm{I}+2 c t)>4 b c t+4 c t, \\
& a(\mathrm{I}+2 c t)^{2}-4 b c t-4 c t>0,
\end{aligned}
$$

and hence $a^{2}(\mathrm{I}+2 c t)^{2}-8 b c t-4 c t(b(a-2)+a)>0$. Thus the numerator of the fraction $\mathrm{I}+\mathrm{L}$ is positive, so that $\mathrm{I}+\mathrm{L}>0$ and $\mathrm{L}>-\mathrm{I}$.

Similarly, since

and

$$
\begin{aligned}
& a(\mathrm{I}+2 c t)+2 a c t(\mathrm{I}+2 c t)>2+8 b c^{2} t^{2}, \\
& a(\mathrm{I}+2 c t)^{2}-2-8 b c^{2} t^{2}>0 \\
& a^{2}(\mathrm{I}+2 c t)^{2}-8 b c t-2(4 b c t(a c t-\mathrm{I})+a)>0 .
\end{aligned}
$$

Thus $\mathrm{I}+\mathrm{M}>0$ and $\mathrm{M}>-\mathrm{I}$.

When $\mathrm{H}<\mathrm{A}, \mathrm{H}<\mathrm{B}$, the same relations hold but with the inequality signs reversed, so that the numerators of $L$ and $M$ are positive. But since then $\mathrm{H}^{2}<\mathrm{AB}$, the denominators are negative, and $\mathrm{L}<0$ and $M<0$ are still true. Similarly, $L>-I$ and $M>-I$, so that for all values of the viabilities leading to non-trivial equilibria

$$
-\mathrm{I}<\mathrm{L}<0 \text { and }-\mathrm{I}<\mathrm{M}<0 \text {. }
$$

Now the condition for stability is $\left|-\mathrm{L} \pm \sqrt{\mathrm{L}^{2}-4 \mathrm{M}}\right|<2$. Knowing the possible values of $\mathrm{L}$ and $\mathrm{M}$, it is apparent that an equivalent condition is

$$
-\mathrm{L}+\sqrt{\overline{\mathrm{L}}^{2}-4 \mathrm{M}}<2,
$$

whence

$$
\begin{aligned}
& \sqrt{\mathrm{L}^{2}-4 \bar{M}}<2+\mathrm{L}, \\
& \mathrm{L}^{2}-4 \mathrm{M}<4+4 \mathrm{~L}+\mathrm{L}^{2},
\end{aligned}
$$

and

$$
\mathrm{I}+\mathrm{L}+\mathrm{M}>\mathrm{o} \text {. }
$$

Hence $\mathrm{H}>\mathrm{A}, \mathrm{H}>\mathrm{B}$ are necessary conditions for stability. The 
condition for instability is similarly

whence

$$
-\mathrm{L}+\sqrt{\overline{\mathrm{L}^{2}-4 \mathrm{M}}}>2,
$$

Therefore $\mathrm{H}<\mathrm{A}, \mathrm{H}<\mathrm{B}$ are necessary conditions for instability, and hence $\mathrm{H}>\mathrm{A}, \mathrm{H}>\mathrm{B}$ are necessary and sufficient conditions for stability.

\section{APPLICATION TO WALLACE'S DATA}

This model may now be applied to Wallace's data.

Wallace's experiments were of two kinds. First, he ran four population cages, two at $16 \frac{1}{2}^{\circ} \mathrm{C}$. and two at $25^{\circ} \mathrm{G}$., in which the foundation stocks consisted of known numbers of the several genotypes. Samples of eggs were taken from these cages every month or so, and assayed in order to determine the frequencies of the genotypes. Secondly, in a series of subsidiary experiments, he made quantitative estimates of the following components of fitness of the different genotypes: larval competition; longevity; fecundity (female); sexual activity (male); and egg hatchability (female). By multiplying these estimates together he obtained an overall selective value for each genotype, and he quoted the maximum and minimum values that he considered possible at each temperature. These viabilities were given relative to that of the normal in males and of the heterozygote in females. Wallace multiplied his values for the relative viabilities of the abnormal males by a factor of two in an attempt to express the selective advantage due to the abnormal sex ratio amongst their offspring. However, this advantage has already been allowed for in the present model, so that it is necessary to remove this factor of two before using these values. Wallace's mean viabilities at each temperature, expressed relative to that of the normal in each sex, and with the factors of two omitted, are given in table 2. Darlington and Dobzhansky (1942) studied the effect of temperature on the parameter $t$ and found a value of 0.9382 at $25^{\circ} \mathrm{C}$. and a value of 0.9878 at $16 \frac{1}{2}^{\circ} \mathrm{C}$. The equilibria, which are stable, corresponding to these values of $a, b, c$ and $t$ are given in table 3 .

In Wallace's population cages the $\mathrm{X}_{r}$ chromosome was lost completely at $25^{\circ} \mathrm{C}$. (and hence the gene ratios were all zero), whilst at $16 \frac{1}{2}^{\circ} \mathrm{C}$. the following gene ratios were obtained from samples of eggs taken after approximately twelve generations of selection (when the experiment was ended):

Cage 12. Female: 0.062; Male: 0.095.

Cage 13. Female: 0.048; Male: 0.063.

Even when the sizes of the egg samples are taken into account it is apparent that these observed ratios are incompatible with the theoretical equilibrium ratios. It must therefore be concluded that either the present model is inadequate, or Wallace's values for the overall 
viabilities differ from the viabilities which actually pertained in the population cages. Partial vindication of the model could be obtained by seeing if viabilities exist that would make the model populations approach the observed equilibria at the correct rates. But before doing this it is appropriate to examine the limitations of the model, of which there are four main ones:

(1) Population and progeny sizes are assumed infinite.

(2) Generations do not overlap.

(3) Parental expenditures on individuals of either sex are set equal.

(4) Viability is assumed not to be sex-differential during the period of parental expenditure.

TABLE 2

Wallace's mean viabilities

\begin{tabular}{|c|c|c|c|c|c|}
\hline \multirow{2}{*}{ Temperature } & \multicolumn{5}{|c|}{ Genotypes } \\
\hline & $\underset{I}{X X}$ & $\underset{a}{\mathrm{XX}_{r}}$ & $\underset{b}{\mathrm{X}_{r} \mathbf{X}_{r}}$ & $\underset{I}{X Y}$ & $\underset{c}{\mathrm{X}_{r} \mathrm{Y}}$ \\
\hline $25^{\circ} \mathrm{C}$. & I & $3 \cdot 384$ & 0.059 & I & 0.355 \\
\hline $16 \frac{1}{2}^{\circ} \mathrm{C}$ & I & $\mathrm{I} \cdot 263$ & $0 \cdot 39^{2}$ & I & 0.711 \\
\hline
\end{tabular}

TABLE 3

Equilibrium gene ratios with Wallace's viabilities

\begin{tabular}{|c|c|c|c|c|}
\hline \multirow{2}{*}{ Temperature } & \multicolumn{2}{|c|}{ Before genotypic selection } & \multicolumn{2}{|c|}{ After genotypic selection } \\
\cline { 2 - 5 } & Female & Male & Female & Male \\
\hline $25^{\circ} \mathrm{C}$. & 0.537 & 0.654 & 0.654 & 0.232 \\
$161^{\circ} \mathrm{C}$. & 0.637 & 0.536 & 0.536 & $0.38 \mathrm{r}$ \\
\hline
\end{tabular}

That the first limitation is unimportant is shown by Barker's computations on an electronic digital computer, by which he compared the changes in gene frequency due to selection in infinite populations and populations the size of Wallace's. Although, as will be mentioned, Barker's work is open to criticism in some respects, the comparisons remove any doubt that the assumption of infinite population and progeny sizes is important in this instance.

The fact that the model does not include the overlapping of generations is unlikely to matter very much, especially in the present context where there are so few generations.

The third limitation is also reasonable: it is unlikely that parental 
expenditure is significantly sex-differential in Drosophila species, since sexual dimorphism is not noticeable until well after parental expenditure must have ceased, and also since the normal sex-ratio is about one-half.

As far as the fourth limitation is concerned, in Drosophila all the fertilised eggs are laid whether they are viable or not, so that sexdifferential viability before the end of the period of parental expenditure does not exist. It could be argued that parental expenditure on inviable eggs differs from that on viable eggs, but, as Gershenson showed, such a small proportion of eggs is inviable that this could hardly be important.

It is thus apparent that, given correct viabilities, the model should be a good approximation to reality, and it must be concluded that Wallace's viabilities are inadequate estimates of the relative selection pressures involved.

In order to discover whether reasonable values for the viabilities exist which would make the model compatible with Wallace's experimental findings, the original recurrence relations in the genotype frequencies were programmed onto EDSAC II, the Cambridge University Mathematical Laboratory's high-speed electronic digital computer. The following variables could be set at the start of the programme:

$u, v, w, x$ and $y$, the initial genotype frequencies;

$a, b$ and $c$, the relative viabilities;

and $t$, the proportion of females born to $\mathrm{X}_{r} \mathrm{Y}$ males.

The output, which could be printed to any reasonable number of figures, consisted of the following information, printed every $n$th generation, where $n$ could be set beforehand:

the relative frequencies of the five genotypes;

the sex ratio;

the gene frequencies in males, females, and in the whole population; and " $\mathrm{T}$ ".

The programme could be set to print this information either before or after genotypic selection, and to run for any number of generations.

It was not considered worthwhile to write a comprehensive programme which would search for the viabilities which give the best fit to Wallace's selection data. Thus there may be better values than those finally arrived at, so that the viabilities quoted below cannot be considered proper estimates. Nevertheless, the investigation showed that it is possible to simulate Wallace's results satisfactorily, with certain reservations.

Figs. I, 2, 3 and 4 show the simulated selection response curves together with the 95 per cent. fiducial limit curves, in terms of genotype frequencies before zygotic selection, for Cages IO, II, I2 and I3. 


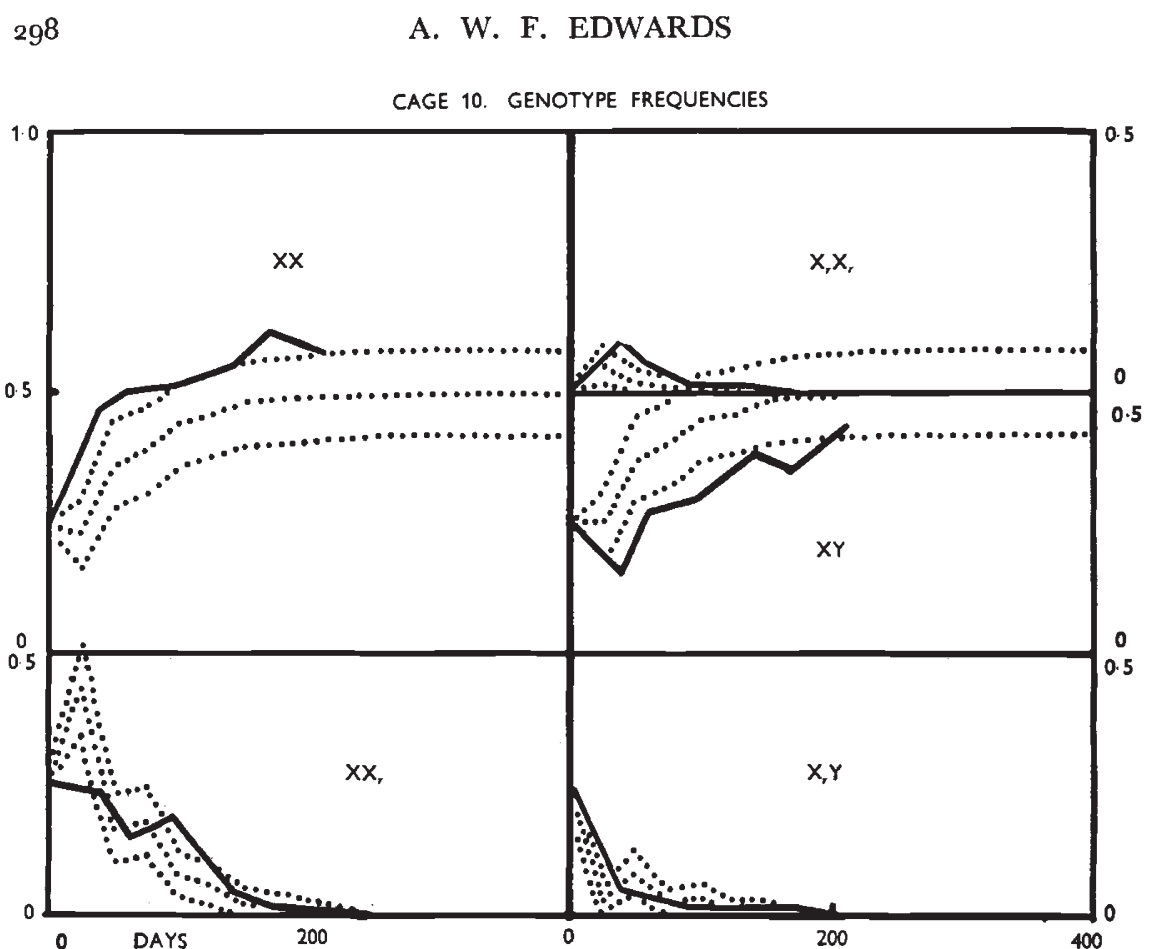

Fig. 1.

CAGE 11. GENOTYPE FREQUENCIES

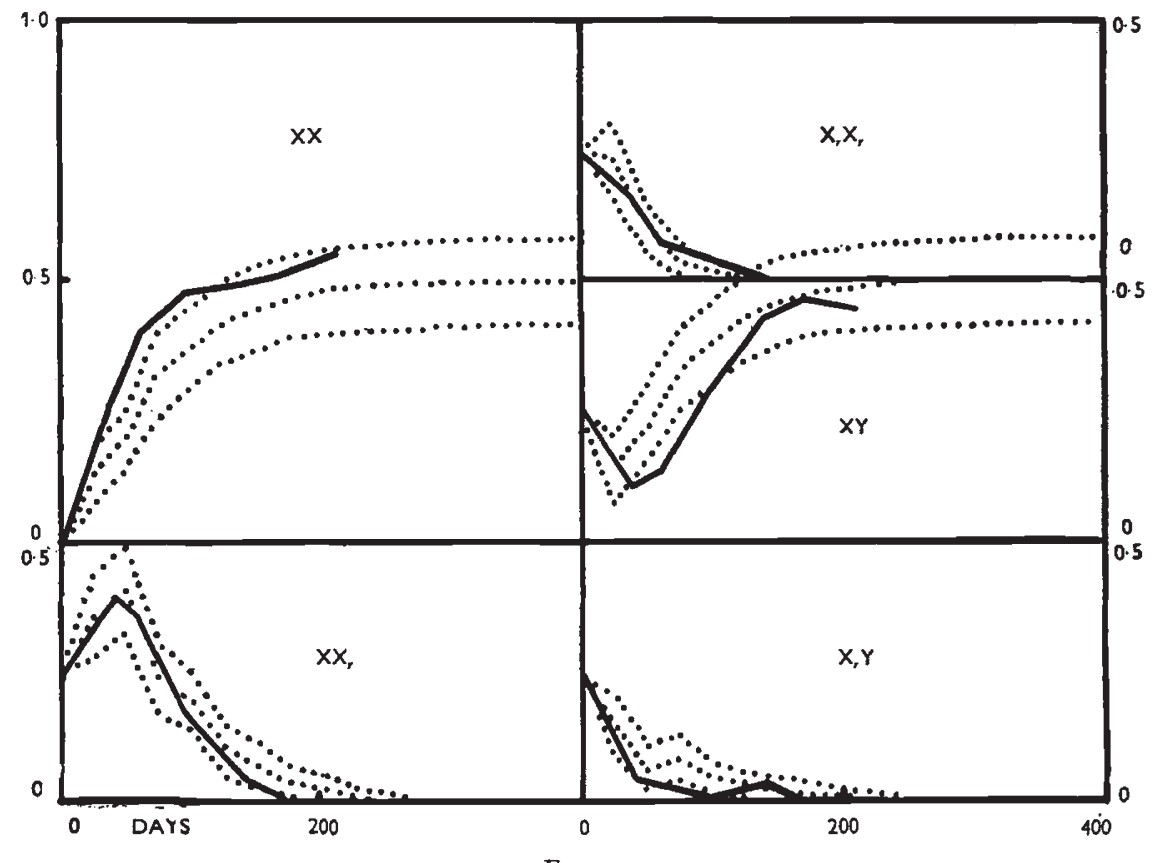

FIG. 2. 
CAGE 12. GENOTYPE FREQUENCIES

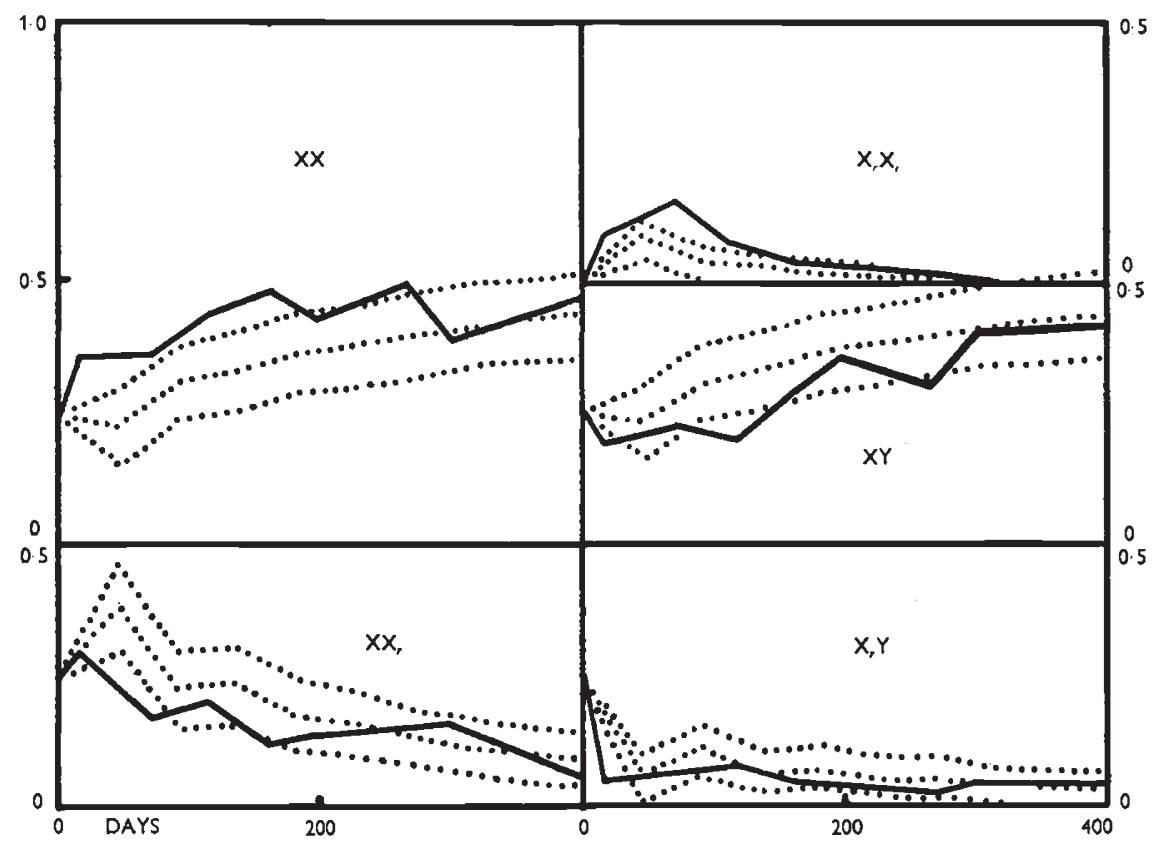

FIG. 3.

CAGE 13. GENOTYPE FREQUENCIES

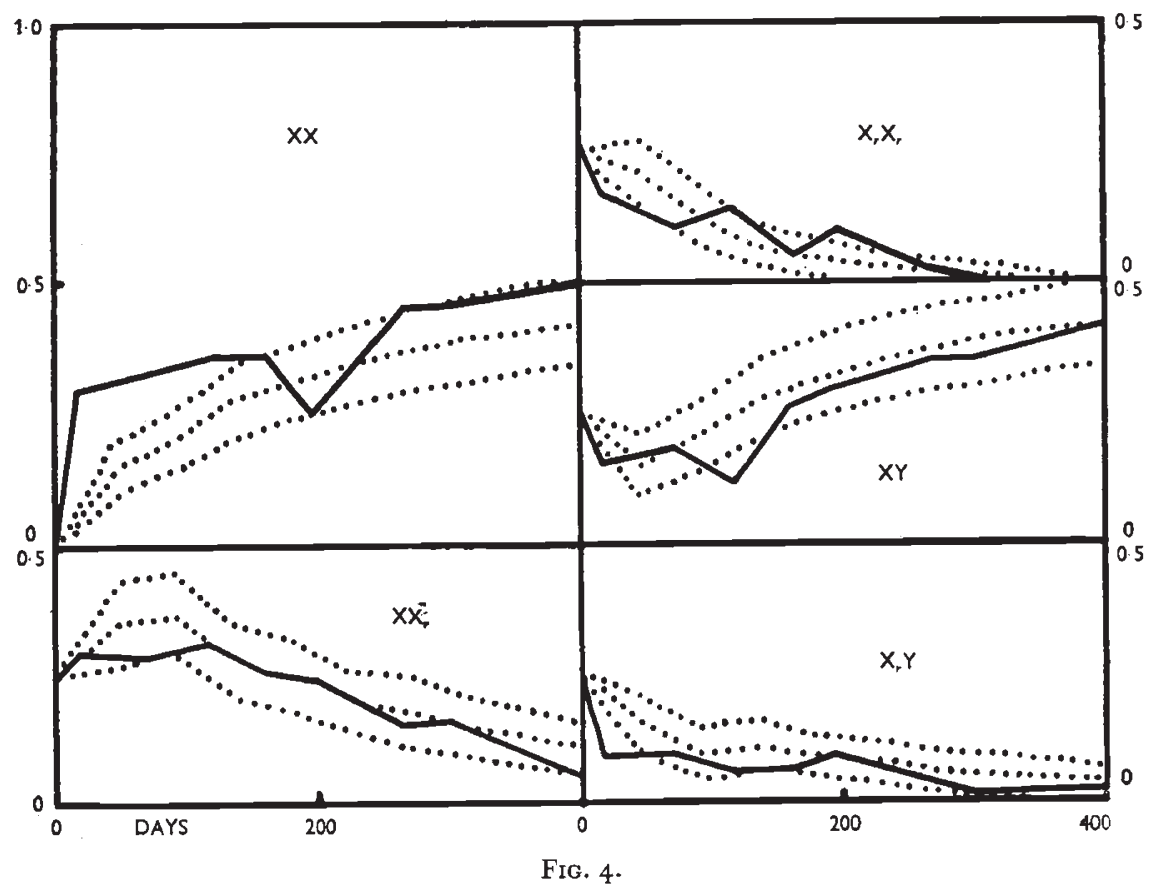


Cages Io and I I had been maintained at $25^{\circ} \mathrm{C}$., so that $t$ was taken to be 0.9382 for them, and Cages 12 and 13 at $161^{\circ} \mathrm{C}$., for which $t$ was taken to be 0.9878 . The simulated curves were obtained using the following viabilities:

$$
\begin{aligned}
& \text { Cages Io and I I: } a=0.3 ; b=0 ; c=0.95 \\
& \text { Cages I } 2 \text { and I } 3: a=0.7 ; b=0 ; c=0.7 .
\end{aligned}
$$

The viabilities at $25^{\circ} \mathrm{C}$. correspond closely to those suggested by Barker $(0.4$, o and 0.95$)$, which were indeed used as a first approximation.

In each of the four cages the simulated response curves agree well with those obtained experimentally by Wallace, except that the predicted frequency of XX individuals is consistently too high, whereas that of XY individuals is too low. On the present model it is easy to show that, whatever the viabilities, the expected frequency of XX must be less than that of $\mathrm{XY}$ except when the $\mathrm{X}_{r}$ chromosome has been eliminated, in which case the frequencies are equal. But in practice the reverse is true: it seems as though the assumption that normal individuals breed with a sex-ratio of one-half is false, and this is borne out by Wallace's populations kept at $25^{\circ} \mathrm{C}$., in which the following numbers of male and female progeny were counted after $\mathrm{X}_{r}$ had apparently been eliminated:

Cage ro: 64 males and 86 females;

Cage I I : 67 males and 83 females.

There is clearly no heterogeneity between the cages, and the combined sex-ratio of I3I : I 69 is significantly different from I : I at the 5 per cent. level. Evidently a model which took this abnormal sex ratio into account would fit the data even more closely than the present one. Wallace did not comment on this sex-ratio, but Gershenson, who is the only other writer on the subject to quote comparable sexratios, found no deviation from I : I. It therefore seems likely that this abnormality is confined to Wallace's experimental populations, and is perhaps due to a factor such as overcrowding.

As can be seen from the figures, the simulated selection curves approach fixation of the normal gene at both temperatures, so that the apparent equilibria of Cages 12 and 13 are probably fortuitous.

\section{ESTIMATION OF VIABILITIES IN NATURAL POPULATIONS}

It is interesting to investigate what viabilities would give rise to an equilibrium $\mathrm{X}_{r}$ chromosome frequency of $p$.

Working in terms of gene ratios at maturity,

and

$$
r_{\text {ef }}=\frac{a(\mathrm{I}+2 c t)-2}{a(\mathrm{I}+2 c t)-4 b c t}
$$

$$
r_{e m}=c r_{e f} \text {. }
$$


Dobzhansky reported that there was no significant difference between the male and female gene ratios in any sample from the natural populations he studied, so that $r_{e m}=r_{e f}$ and $c=\mathrm{I}$. $t$ may be taken to be equal to 1 , whence

$$
r_{e m}=r_{e f}=p /(1-p)=(3 a-2) /(3 a-4 b) .
$$

Supposing that the inviability effect of the $\mathrm{X}_{r}$ chromosome is additive, $(\mathrm{I}-b)=2(\mathrm{I}-a)$, or $2 a-b=\mathrm{I}$.

$$
\begin{array}{ll}
\text { Hence } & a=(2 p+2) /(2 p+3) \\
\text { and } & b=(2 p+1) /(2 p+3) .
\end{array}
$$

Table 4 gives some examples of values of $p, a$ and $b$ that satisfy these relations. These viabilities lead to stable equilibria. Sturtevant and Dobzhansky, and Dobzhansky, reported gene frequencies ranging from

TABLE 4

Equilibrium gene frequencies corresponding to various viabilities

\begin{tabular}{|c|c|c|c|}
\hline \multicolumn{3}{|c|}{ Viabilities } & Gene frequency \\
\hline$a$ & $b$ & $c$ & $p$ \\
\hline & & & \\
\hline 0.67 & 0.33 & I & 0.0 \\
0.69 & 0.38 & I & $0 \cdot 1$ \\
$0 \cdot 71$ & $0 \cdot 4 \mathrm{I}$ & I & $0 \cdot 2$ \\
$0 \cdot 72$ & $0 \cdot 44$ & I & $0 \cdot 3$ \\
$0 \cdot 74$ & 0.47 & I & $0 \cdot 4$ \\
\hline
\end{tabular}

zero to 30 per cent. in natural populations of Drosophila pseudoobscura, and the suggested viabilities could account for these. Moreover, small changes in the viabilities lead to relatively large changes in the gene frequencies, so that both the wide range of apparent equilibria and the changes in gene frequency with time are to be expected.

\section{CRITICISM OF PREVIOUS WORK}

It was mentioned in the introduction that previous treatments of this subject have not been entirely satisfactory. The first attempt at a model for the "sex-ratio" locus was made by Bennett. He put forward a model appropriate to a sex-linked locus without gametic selection, but then committed the error of applying this model to the present case, in which gametic selection, or an equivalent phenomenon, occurs. In effect he confounded gametic and zygotic selection, an erroneous procedure in this case, as will be shown below.

Unfortunately it happens that his results are, on the surface, reasonable, and some are indeed correct. For example, the characteristic equation for the approach of the gene ratios at maturity to their equilibrium values contains $c$ and $t$, the two viabilities in question, 
always confounded as the product $c t$, so that the rate of approach near equilibrium, and the stability of the equilibrium, are correctly given by Bennett's equations. Similarly, the equilibrium gene ratio at maturity in females is correct, but that in males is wrong because in the expression for it $c$ occurs unaccompanied by $t$. As an example of the erroneous results from Bennett's model, the equilibrium situation at maturity using Wallace's maximum selective values at $25^{\circ} \mathrm{C}$. is

TABLE 5

Equilibrium frequencies at maturity on the two models

\begin{tabular}{|c|c|c|c|c|c|c|c|}
\hline & & \multirow[b]{2}{*}{. } & \multirow[b]{2}{*}{. } & \multirow{2}{*}{$\begin{array}{c}\text { Bennett } \\
0 \cdot 149\end{array}$} & \multirow{2}{*}{$\begin{array}{c}\text { Edwards } \\
0 \cdot 172\end{array}$} \\
\hline $\mathrm{XX}$ & . & - & • & & & & \\
\hline $\mathrm{XX}_{r}$ & • & . & . & . & . & 0.528 & 0.612 \\
\hline $\mathrm{X}_{r} \dot{\mathrm{X}}_{r}$ & • & - & . & . & . & 0.003 & 0.003 \\
\hline$X Y$ & • & . & . & - & - & 0.218 & 0.172 \\
\hline$X_{r} Y$ & & . & . & . & . & 0.102 & 0.040 \\
\hline Sex-rat & atio & $\cdot$ & . & . & . & 0.320 & 0.212 \\
\hline Male $\mathrm{g}$ & gene & freque & ency & . & . & 0.319 & $0 \cdot 190$ \\
\hline Female & le ge & e freq & uency & - & . & 0.393 & 0.393 \\
\hline Overal & all ge & freq & uency & . & . & 0.379 & $0.3^{69}$ \\
\hline
\end{tabular}

given for the two models in table 5 , it being presumed in both cases that $\mathrm{X}_{r} \mathrm{Y}$ males produce no sons at all.

In the case of results given before zygotic selection, Bennett's model leads to the correct gene ratios in males and females at each generation, and hence at equilibrium, but since the sex-ratio of the population is, on his model, then always one-half, the overall gene ratio is incorrect. The genotype frequencies are also wrong.

TABLE 6

Equilibrium frequencies at fertilisation on the two models

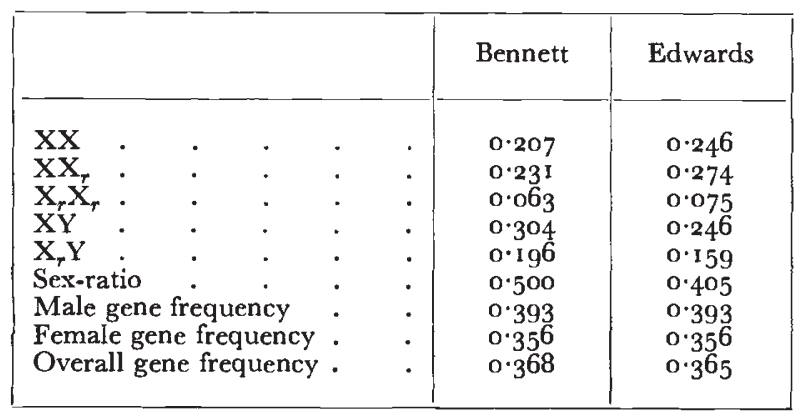

Table 6 gives a comparison similar to that in table 5 , but with frequencies before genotypic selection. In view of the inapplicability of Bennett's model to the present problem it seems best to disregard it in this connection.

Barker investigated the problem stochastically on an electronic computer, and in his programme he made allowance for both gametic and zygotic selection individually. $\mathrm{He}$ also ran a programme, for 
comparison, in which the two forms of selection were confounded, as in Bennett's model, and concluded that in his work " the methods of simulation of selection used are adequate and that specific or overall [confounded] selective values may be used to study any given genetic situation ". He was misled into making the latter part of this statement by the fact that he happened to be working only in terms of the gene frequencies in males and females before zygotic selection, which, as has been stated above, are the same in both models. Had he investigated the genotype frequencies, or the sex ratio, discrepancies would have been apparent. So far as his own model goes, conclusions drawn from it seem to be valid.

Shaw contributed a short article on the problem, in which he did not appreciate Bennett's errors. He agreed with Bennett that the equilibrium male gene frequency at maturity, using Wallace's maximum viabilities at $25^{\circ} \mathrm{C}$., was " about 30 per cent.", whereas the correct value is 19 per cent. (see table 5). He also stated that "once the equilibrium frequency of the "sex-ratio" males is known, that of the other genotypes is fully determined". This statement is only true if one also knows the sex ratio.

Sprott (1957) set up a model for any number of alleles at a sexlinked locus, and, working in terms of the male and female gene frequencies, established the conditions for stable equilibrium. $\mathrm{He}$ did not apply this model to any real situation. His stability conditions are no more than a slight simplification of the determinantal equation for the latent roots of the generation matrix, and are not given as simple inequalities in the viabilities. He gave an example of a stable equilibrium for two alleles in which the gene frequencies agree with those calculated by the method given in the present paper. However, he gave the corresponding female genotype frequencies incorrectly, owing to the fact that he did not appreciate that he was working in terms of the gene frequencies after selection, as is clear from his original equations. The female genotype frequencies he quoted are those before selection.

\section{SUMMARY}

In Drosophila pseudoobscura the X-linked condition "sex-ratio" causes males carrying it to produce few or no sons, but nearly twice as many daughters as are produced by normal males (Gershenson, 1928; Sturtevant and Dobzhansky, 1936). In the absence of differential viability one might expect it to increase in a population until there were no males left, yet equilibria, with gene frequencies up to 30 per cent., have been found in natural populations (Sturtevant and Dobzhansky, I936; Dobzhansky, I943). Wallace (1948) conducted a series of experiments to determine the viabilities, and set up some population cages to follow the progress of the gene. In these cages the gene was either eliminated, or was at a very low frequency when the experiment was ended. Bennett (1958) put forward a mathematical 
model for a sex-linked locus which he applied to Wallace's findings, but examination of his model reveals an error which makes it inapplicable to this situation: he confounded gametic and genotypic viabilities, a course which invalidates some of his findings. The present paper describes a more appropriate model, which has been used to study the polymorphism. It is shown that Wallace's viabilities fit neither the natural nor his experimental populations, and new viabilities are suggested for each case.

Acknowledgments. - I wish to thank the Director of the Mathematical Laboratory, University of Cambridge, for permission to use EDSAC II, the high-speed electronic digital computer, and Drs W. F. Bodmer and K. E. Machin for helpful discussions on the proof of Bennett's stability conditions.

\section{REFERENCES}

BARKER, J. S. F. 1958. Simulation of genetic systems by automatic digital computers. IV. Selection between alleles at a sex-linked locus. Aust. F. Biol. Sci., $I I, 613-625$.

BENNETT, J. H. 1958. The existence and stability of selectively balanced polymorphism at a sex-linked locus. Aust. F. Biol. Sci., II, 598-6o2.

BODMER, W. F., AND EDWARDS, A. W. F. Ig6o. Natural selection and the sex ratio. Ann. Hum. Genet., Lond., 24, 239-244.

DARLington, G. D., AND DOBZHANSKy, TH. I942. Temperature and "sex-ratio" in Drosophila pseudoobscura. Proc. Nat. Acad. Sci., 28, 45-48.

Dobzhansky, тн. 1943. Genetics of natural populations. IX. Temporal changes in the composition of populations of Drosophila pseudoobscura. Genetics, 28, 162-186,

Gershenson, s. 1928. A new sex-ratio abnormality in Drosophila obscura. Genetics, I3, 488-507.

MORGAN, T. H., BRIDGES, C. B., AND STURTEVANT, A. H, 1925. The genetics of Drosophila. Bibl. Genet., 2, I-262.

sHaw, R. F. 1959. Equilibrium for the sex-ratio factor in Drosophila pseudoobscura. Amer. Nat., 93, 385-386.

SPRotT, D. A. I957. The stability of a sex-linked allelic system. Ann. Hum. Genet., Lond., 22, I-6.

STURTevant, A. H., AND Dobzhansky, TH. 1936. Geographical distribution and cytology of " sex ratio" in Drosophila pseudoobscura and related species. Genetics, $21,473-490$.

WAllace, B. 1948. Studies on " sex-ratio" in Drosophila pseudoobscura. I. Selection and "sex-ratio." Evolution, 2, 189-217. 